\title{
Deformation waves from distant earthquakes as a trigger mechanism for activating geodynamic processes in rock mass
}

\author{
Vladimir Lugovoy ${ }^{1 *}$, Denis Tsoi $^{1}$, Maksim Rasskazov ${ }^{1}$ and Kamchibek Kozhogulov ${ }^{2}$ \\ ${ }^{1}$ Mining Institute FEB RAS, 51 Turgenev st., Khabarovsk, 680000, Russia; \\ ${ }^{2}$ Institute of Geomechanics and Subsoil Development of the National Academy of Sciences \\ of the Kyrgyz Republic, Bishkek, Kyrgyzstan
}

\begin{abstract}
The results of experimental studies with a laser strainmeter and a multichannel automated geoacoustic rock pressure control system "PROGNOZ ADS" aimed at identifying the nature of the effect of deformation waves from distant earthquakes on the geodynamic activity of the monitored rock mass are presented. The quantitative and energy characteristics of geoacoustic emission before and after the arrival of deformation waves in the controlled rock mass are analyzed. The analysis performed indicates a trigger mechanism of the influence of a distant earthquake on the geodynamic activity of the rock mass. It is noted that the direction of arrival of the deformation wave is an essential factor in the intensification of geodynamic activity in the rock mass. The experiments also revealed the characteristics of rock burst precursors when registering deformation waves in the low-frequency range.
\end{abstract}

Keywords: Anthropogenic seismicity, geomechanical monitoring, laser strainmeter, stress-strain state, deformation waves, trigger mechanism.

\section{Introduction}

The problem of reducing the risk of anthropogenic disasters during large-scale mining operations is relevant for the Far Eastern region of Russia, where deposits that are dangerous due to rock bumps are being developed. Among the enterprises operating rockburst-hazardous deposits is PJSC Priargunskoye Industrial Mining and Chemical Union (PJSC PIMCU) [1]. Here, the uranium deposits of the Streltsov ore field (southeastern Transbaikal) are mined underground [2, 3]. At present, the rock mass of the ore field is largely disturbed by mining operations. The development of the deposits is carried out by four underground mines, where mining operations have reached depths of $500-900 \mathrm{~m}$. The whole spectrum of dynamic manifestations of rock pressure, up to strong and destructive rock bursts, has been recorded there.

As researchers [4-6] have shown, deformation-wave processes in the Earth's crust are a trigger mechanism for various high-energy seismic events (earthquakes, rock bumps, etc.). At the same time, they can be the harbingers of these events. The task of their detection and registration becomes urgent.

*Main author: lygovoy@dst.khv.ru 
The influence of deformation waves on the geoacoustic activity of a rock mass is widely discussed in works related to the study and analysis of seismic processes. Observations show that the environment, to a greater or lesser extent, reacts to various external influences, natural or anthropogenic. To understand the nature of the processes requires the use of comprehensive research methods, including seismic, geoacoustic, deformation methods with the use of appropriate measuring and registration automated systems.

At present, to control the geodynamic state of the rock mass, a multi-level system of integrated geodynamic monitoring has been created and is being improved, which integrates seismic, geoacoustic and deformation methods and measuring sets into a single measuring network $[7,8]$.

To control the deformation field in the ore field and adjacent areas of the rock mass, a laser strainmeter is used in the geomechanical monitoring system.

\section{Laser strainmeter}

The laser strainmeter is located in an underground mine working at a depth of more than $300 \mathrm{~m}$. The optical part of the strainmeter is assembled on the basis of a modified Michelson interferometer of an unequal type with a working arm length of $50 \mathrm{~m}$, oriented to the north-east at an angle of $30^{\circ}$, and a frequency-stabilized laser made by MellesGriott [9]. The interferometer is capable of registering displacements of the Earth's crust with an accuracy of $0.1 \mathrm{~nm}$ in the frequency range from 0 to $1000 \mathrm{~Hz}$ [10-12].

The optical elements of the strainmeter are mounted on two concrete blocks rigidly connected to the rock mass. One of them is equipped with an optoelectronic part of the interferometer, which consists of a frequency-stabilized laser, an extreme control system (registration system and a resonant amplifier) and other structural and optical elements of the laser strainmeter (Fig.1a), the other - with a corner reflector. Between two concrete blocks, the laser beam propagated through an air-filled light guide consisting of joined pipes with an inner diameter of $0.1 \mathrm{~m}$ (Fig. $1 b$ ).
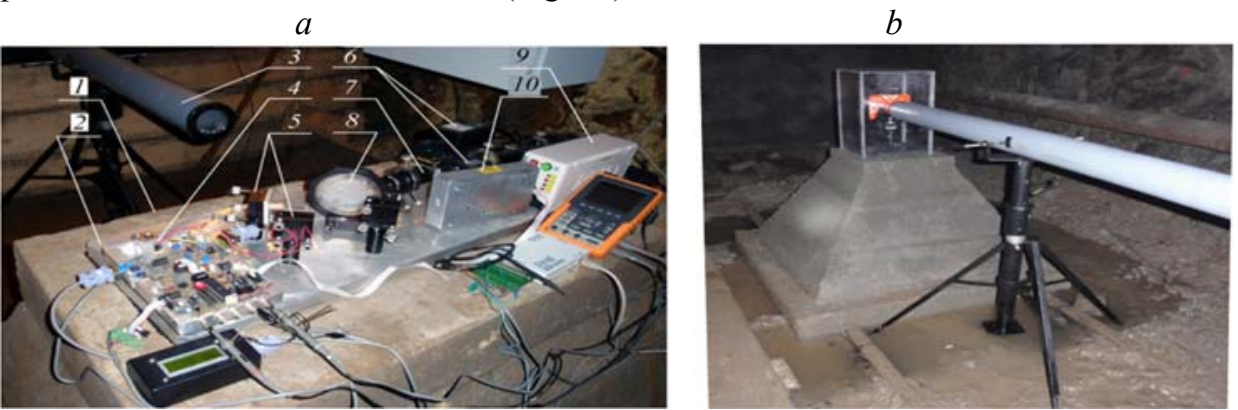

Fig. 1. Laser strainmeter installed at the geodynamic test site in the area of Streltsov ore field: $a$ interferential unit; $b$ - corner reflector and a fragment of an air-filled light guide: 1 - concrete base; 2 - optical bench; 3 - light guide; 4 - registration system; 5 - piezoceramic units; 6 - laser with power supply; 7 - collimator; 8 - dividing plate; 9 - registration system power supply; 10 resonant amplifier.

To ensure the necessary humidity and temperature conditions, the working is divided into two sections: equipment section and light guide section. A Ballu BDH-25L dehumidifier installed in the equipment section provides its humidity at the level of $50-$ $60 \%$. The temperature mode of the equipment section and the light guide section is quite stable, with a temperature variation of $\pm 2{ }^{\circ} \mathrm{C}$, which makes it possible to confidently work with the interference pattern. 


\section{Results}

Experimental studies were conducted with a laser strainmeter and a PROGNOZ ADS multichannel automated geoacoustic rock pressure monitoring system, which allows recording and identifying the parameters of $\mathrm{AE}$ events in the frequency range of $0.5-12$ $\mathrm{kHz}$, in order to reveal the nature of the impact of remote earthquakes on the state of the rock mass in the mining area at the uranium deposits of Streltsov ore field [13].

Figure 2 shows a typical record by a laser strainmeter of the deformation vibrations of Antey deposit from a large remote earthquake with a magnitude of 6.6 that occurred on the western coast of Honshu (Japan) on June 18, 2019 at 22:22:18 local time (time in Krasnokamensk is 9 hours different from universal time). In Figure 2, the arrow marks the time of the earthquake.

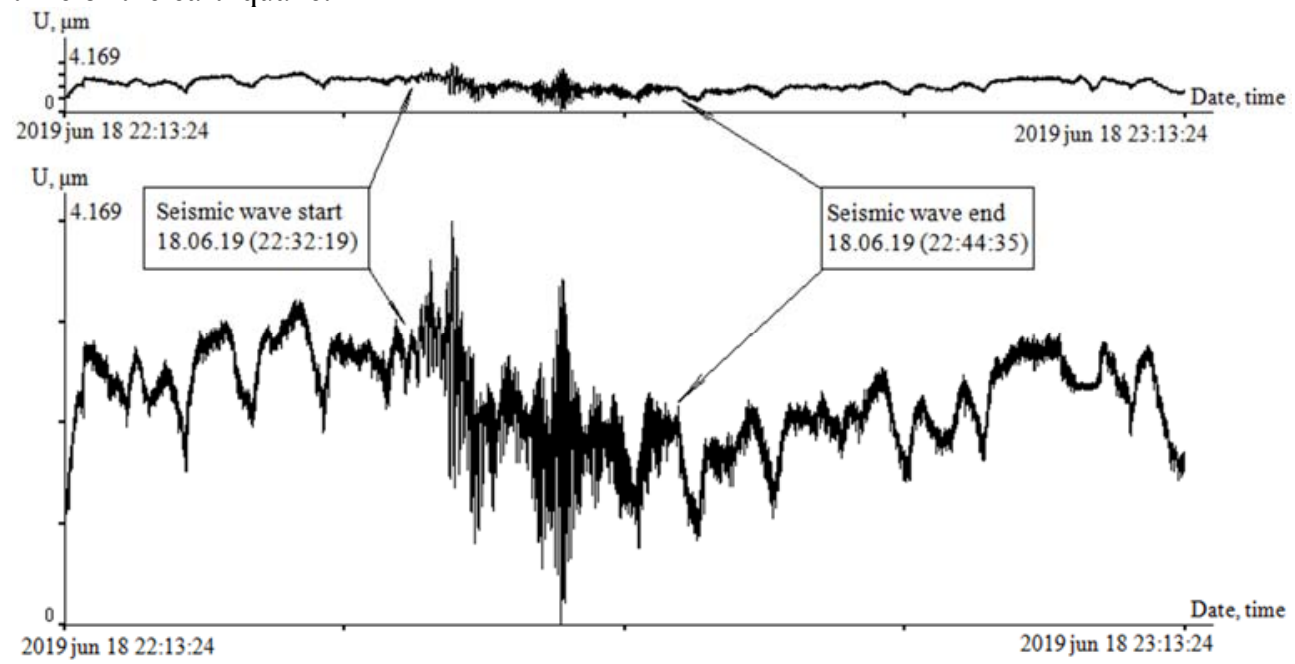

Fig. 2. Section of the recording a signal caused by the earthquake on the west coast of Honshu (Japan), 18.06.2019 at 22:32:19 (magnitude 6.6, focal depth $20 \mathrm{~km}$, coordinates: latitude 38.6, longitude 139.4).

The arrival time of these fluctuations is $22: 32: 19$. The delay time was $10 \mathrm{~min}$, while the calculated "apparent" velocity of the deformation wave is $3,425 \mathrm{~m} / \mathrm{s}$ (the distance from the earthquake source to the strainmeter according to the Planeta Cale website is $2,055 \mathrm{~km}-$ Fig. 3).

Figure 4 shows a 10-day record of a laser strainmeter. During this period, the laser strainmeter recorded a maximum displacement of $212.1 \mu \mathrm{m}$, which, in terms of deformation is $42.4 * 10^{-7}$.

The results of an analysis of the influence of remote earthquakes on the geodynamic activity of Streltsov ore field, obtained with the multichannel automated geoacoustic rock pressure monitoring system "PROGNOZ ADS", are presented in Figures 5 and 6. 


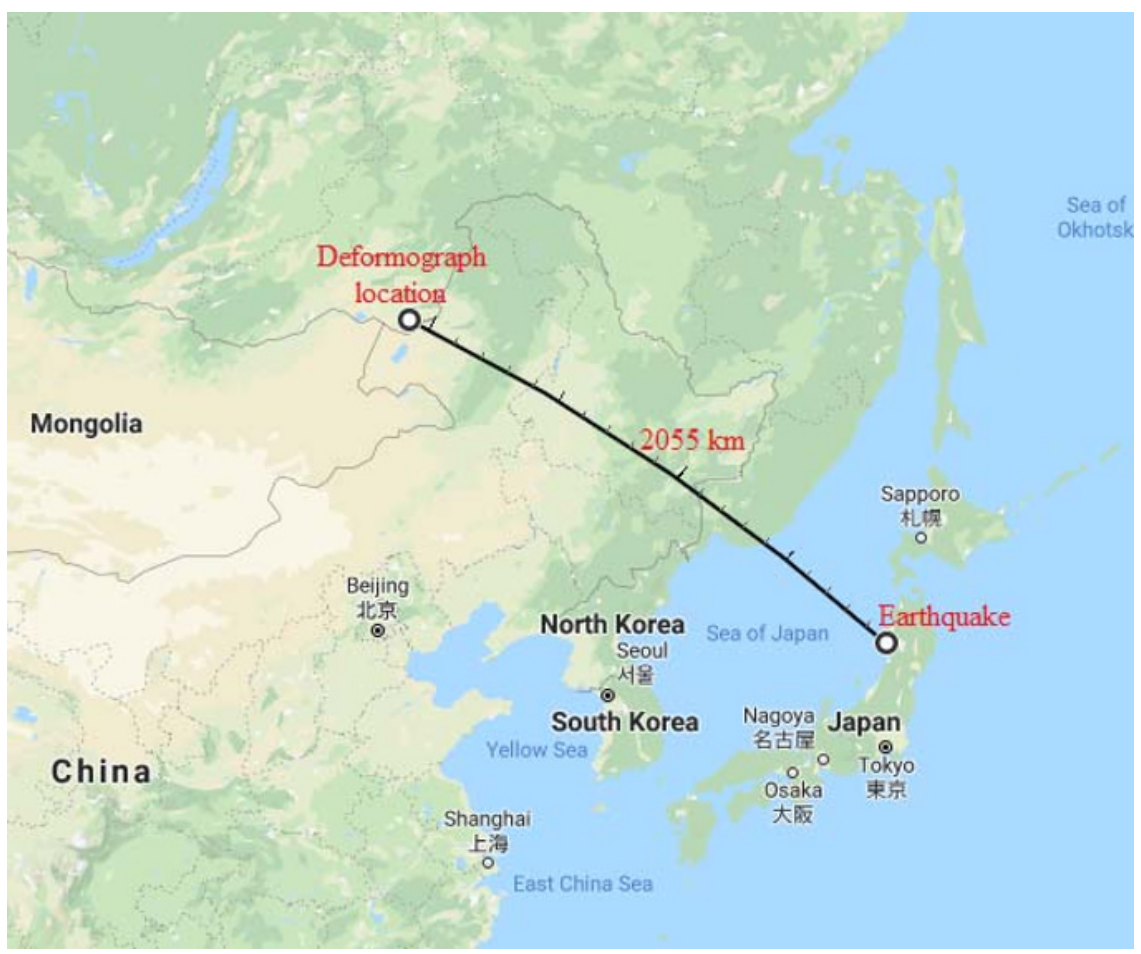

Fig. 3. Distance from the source of the earthquake (west coast of Honshu) to the location of the strainmeter.

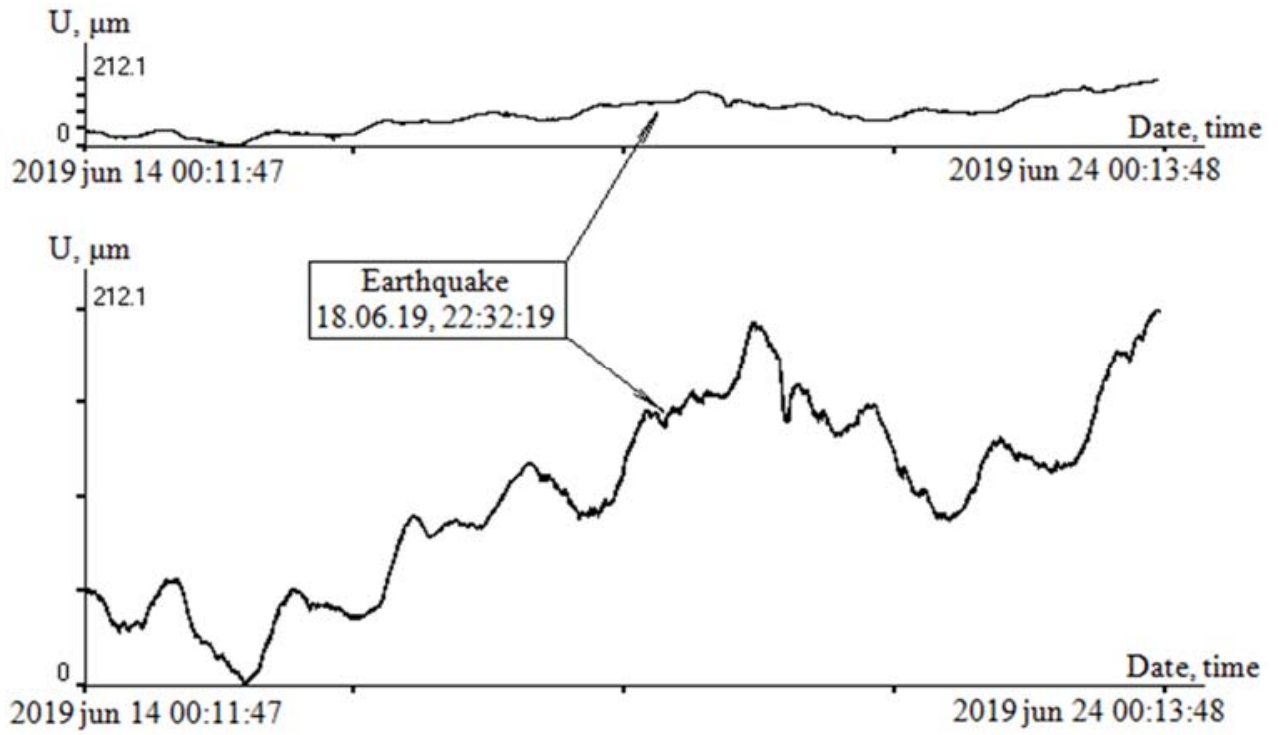

Fig. 4. Section of the laser strainmeter recording for a period of 10 days. 


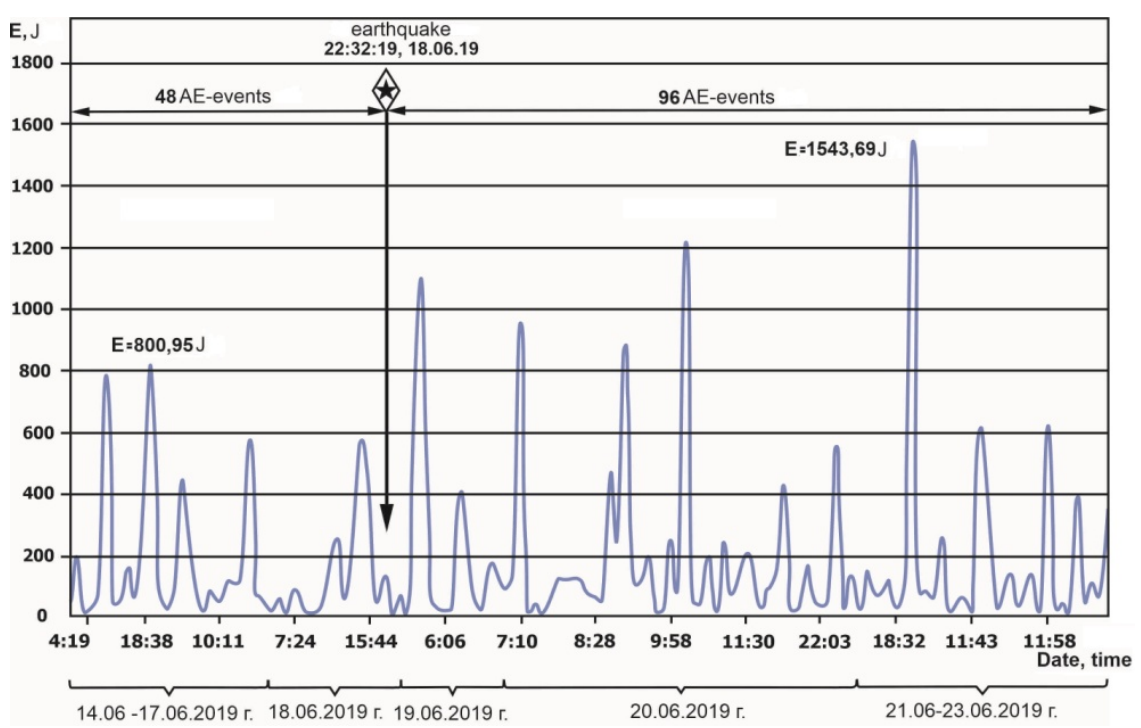

Fig. 5. Graph of geoacoustic activity before and after the earthquake for a period of 10 days.

In Figure 5, the abscissa shows the time, the ordinate is the energy parameter and the arrow marks the time of the earthquake. During 5 days before the earthquake, $43 \mathrm{AE}$ events were detected with a maximum energy of 800.95 J. During the next 5 days after the earthquake, the number of events more than doubled and the energy increased to 1,543.69 J.

At the same time, a significant increase in the number of events was recorded in the same mine working in which they were observed before the earthquake (Fig. 6, a, b).

$a$

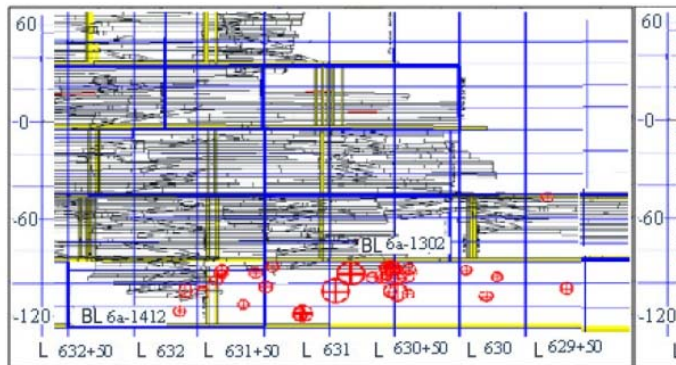

$b$

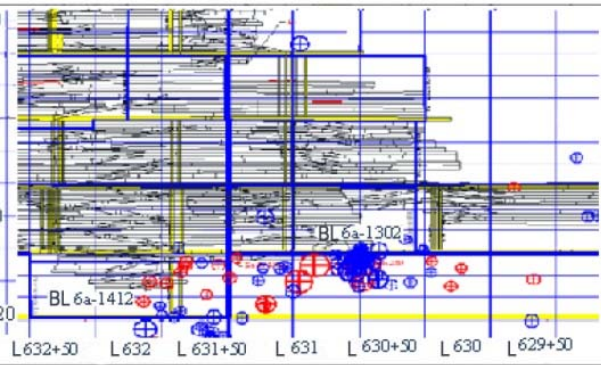

Fig. 6. Geoacoustic activity of Antey field rock mass during 5 days (a) before the earthquake and during 5 days (b) after it.

Thus, seismic waves from distant earthquakes have a significant impact on the geomechanical state of the rock mass, causing an increase in seismoacoustic activity by 2 times or more, and can act as a trigger for large destructive geodynamic phenomena.

Significant distances from earthquakes to the control zone of the rock mass did not allow registering deformation precursors of earthquakes, which could serve as an alarm signal of violations of the continuity of the monitored rock mass.

From the standpoint of studying the possibility of registering precursors of seismic events in the rock mass, of particular interest is the analysis of deformation signals accompanying a rock burst in the zone controlled by a strainmeter, registered on February 29, 2016 (Fig. 7). 


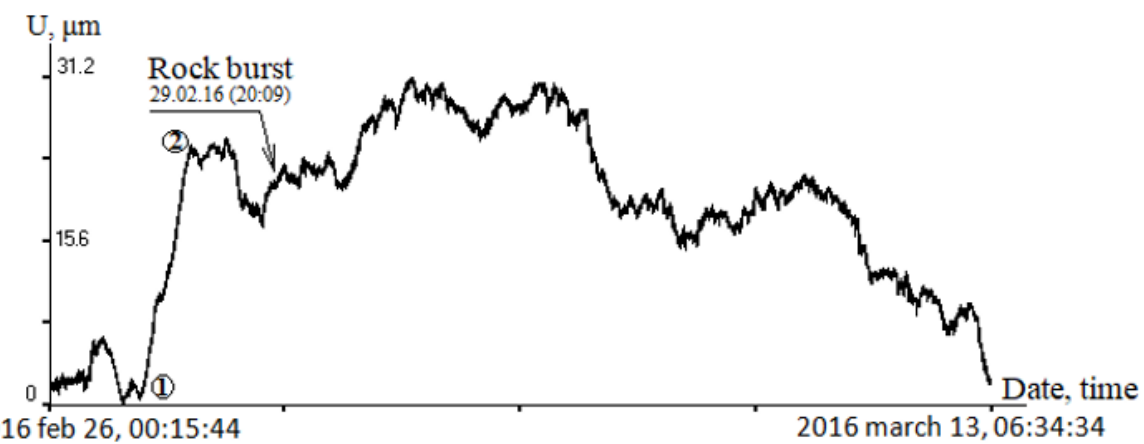

Fig. 7. 2-week laser strainmeter recording.

The external manifestation of a rock burst was significant shaking of the surface of the earth and buildings located on the surface near the mine. When specialists inspected the mine workings in the hazardous area, a hole formation, rock fallout, rock separation were found, and a decision was made to close the unit until the geomechanical situation improves.

The record of the deformation signal from a rock burst by a laser strainmeter (Fig. 7) covers the time interval from February 26 to March 13, 2016. Decimation when analyzing a signal is about 10,000, which determines the frequency range of analysis up to $50 \mathrm{MHz}$.

Interesting is the section of the record marked with numbers 1 and 2 . It should be interpreted as a significant compression of the rock mass preceding a rock burst. Number 1 is the beginning of compression - February 27, 13 hours 33 minutes. Number 2 is the end of compression - February 28, 19 hours 57 minutes. Thus, approximately 1.5 days before the impact, anomalous behavior of the rock mass was recorded in the control zone of the laser strainmeter. Further, until March 13, the laser strainmeter registered the discharge of the rock mass and the return to the initial state, recorded on February 26.

Thus, observation of the deformation signal from a laser strainmeter in the lowfrequency region carries information about the build-up of a high-energy seismic event.

\section{Conclusion}

1. A laser strainmeter for high-precision measurements of the parameters of the deformation field provides control of the geomechanical state of the rock mass in the area of Streltsov ore field: daily and semidiurnal tidal fluctuations were recorded, the manifestation of a long-period periodicity of significant amplitude was recorded, the influence of blasting operations was investigated, the fluctuations of mini-geoblocks located in the area of the mine were recorded, the influence of natural oscillations of the Earth was taken into account, oscillations associated with wind waves of a nearby reservoir were recorded, the influence of distant earthquakes was estimated, and the behavior of the rock mass before, during and after a rock burst was analyzed.

2. As the results of experimental studies with a laser strainmeter and a multichannel automated geoacoustic rock pressure control system "PROGNOZ ADS" show, remote earthquakes are a trigger mechanism for activating geodynamic processes; i.e. they lead to an abrupt change in the quantity and the maximum and average energy of geoacoustic events in the rock mass.

3. It was noted in the experiments that a significant factor in the activation of geodynamic events is the direction of arrival of the deformation wave from the earthquake to the controlled rock mass, which requires further research.

4. The experiments established that the anomalous behavior of the deformation field in the low-frequency region in the working band is often up to $50 \mathrm{MHz}$ for 1.5 days before the 
rock burst. In combination with other characteristics of the deformation field the existence of deformation swing with oscillation periods in the band of 0.5-2 hours 1.5-2 days before high-energy seismic events was experimentally proven; this will ensure the reliability of the forecast of seismic events, the assessment of their quantitative and energy characteristics in order to prevent catastrophic events.

\section{References}

1. Stepan Ustinov, Vladislav Petrov, Valery Poluektov and Vasily Minaev, The $5^{\text {th }}$ International Conference, Sadovsky Institute of Geospheres Dynamics of Russian Academy of Sciences, Moscow, 179-186 (2019)

2. L.P. Ishchukova, Uranium deposits of Streltsov ore field in Transbaikal (Irkutsk: Glazovskaya publishers, 2007)

3. I.Yu. Rasskazov, B.G. Saksin, V.A. Petrov, B.A. Prosekin, Journal of Mining Science, 3, 3-13 (2012)

4. G.G. Kocharyan, V.N. Kostyuchenko, D.V. Pavlov, Physical Mesomechanics, 7(1), 5-22 (2004)

5. V.N. Oparin et al., Methods and systems of seismic deformation monitoring of anthropogenic earthquakes and rock bumps. Vol. 1.2. (Novosibirsk: Publishing house of the SB RAS, 2009)

6. M. West, J.J. Sanchez, S.R. McNutt, Periodically Triggered Seismicity at Mount Wrangell, Alaska, After the Sumatra Earthquake; Science, 308, 1144-1146 (2005)

7. I.Yu. Rasskazov, A.V. Gladyr, P.A. Anikin, V.S. Svyatetskiy, B.A. Prosekin, Mining Journal, 8(2), 9-14 (2013)

8. I.Yu. Rasskazov, V.A. Petrov, A.V. Gladyr, D.V. Tyurin, Mining Journal, 7, 17-21 (2018)

9. G.I. Dolgikh, V.E. Privalov, Lasers. Laser systems (Vladivostok: Dalnauka, 2009)

10. G.I. Dolgikh, I. Yu. Rasskazov, V.A. Lugovoy, P.A. Anikin, D.I. Tsoi, V.A. Shvets, S.V. Yakovenko, Instruments and experimental techniques, 5, 138-139 (2013)

11. D.I. Tsoi, M.I. Rasskazov, A.A. Tereshkin, Problems and prospects of integrated development and conservation of the subsoil, 136-139 (2018)

12. I.Y. Rasskazov, V.A. Lugovoy, B.G. Saksin, D.I. Tsoi, G.I. Dolgikh, S.G. Dolgikh, V.A. Petrov, Journal of Mining Science, 52(6), 1052-1059 (2016)

13. Vladimir Lugovoy, Grigoriy Dolgikh, Denis Tsoy, Andrey Gladyr and Maksim Rasskazov, The $5^{\text {th }}$ International Conference, Sadovsky Institute of Geospheres Dynamics of Russian Academy of Sciences, Moscow, 357-366 (2019) 